\title{
Kidney Cancer Research Network of Canada (KCRNC) consensus statement on the role of cytoreductive nephrectomy for patients with metastatic renal cell carcinoma
}

Ross J. Mason ${ }^{1}$; Lori Wood ${ }^{2}$; Anil Kapoor ${ }^{3}$; Naveen Basappa ${ }^{4}$; George Bjarnason ${ }^{5}$; Stephen A. Boorjian ${ }^{6}$; Rodney H. Breau ${ }^{7}$; Ilias Cagiannos ${ }^{7}$; Michael A.S. Jewett ${ }^{8}$; Pierre I. Karakiewicz ${ }^{9}$; Wassim Kassouf ${ }^{10}$; Christian Kollmannsberger ${ }^{11}$; Aly-Khan A. Lalani ${ }^{12}$; Jean-Baptiste Lattouf ${ }^{9}$; Luke T. Lavallée ${ }^{7}$; Stephen Pautler ${ }^{13}$; Nicholas Power $^{13}$; Patrick Richard $^{14}$; Alan So ${ }^{15}$; Simon Tanguay ${ }^{10}$; Ricardo A. Rendon ${ }^{1}$

${ }^{1}$ Department of Urology, Dalhousie University, Halifax, NS, Canada; ${ }^{2}$ Division of Medical Oncology, Dalhousie University, Halifax, NS, Canada; ${ }^{3}$ Division of Urology, McMaster University, Hamilton, ON, Canada; ${ }^{4}$ Division of Medical Oncology, University of Alberta, Edmonton, AB, Canada; ${ }^{5}$ Division of Medical Oncology, University of Toronto, Toronto, ON, Canada; ${ }^{6}$ Department of Urology, Mayo Clinic, Toronto, ON, Canada; ${ }^{7}$ Division of Urology, University of Ottawa, Ottawa, ON, Canada; ${ }^{8}$ Division of Urology, University of Toronto, Toronto, ON, Canada; ${ }^{9}$ Département de Chirurgie (Urologie), Université de Montréal, Montreal, QC, Canada; ${ }^{10}$ Division of Urology, McGill University, Montreal, QC, Canada; ${ }^{11}$ Division of Medical Oncology, University of British Colombia, Vancouver, BC, Canada; ${ }^{12}$ Department of Oncology, McMaster University, Hamilton, ON, Canada; ${ }^{13}$ Division of Urology, Western University, London, ON, Canada; ${ }^{14}$ Division of Urology, Université de Sherbrooke, Sherbrooke, QC, Canada; ${ }^{15}$ Department of Urologic Sciences, University of British Colombia, Vancouver, BC, Canada

Acknowledgements: The authors would like to acknowledge Larry Prokop from Mayo Clinic libraries (Rochester, MN) for performing the comprehensive literature search utilized in the development of this document.

Cite as: Can Urol Assoc J 2018 December 21; Epub ahead of print. http://dx.doi.org/10.5489/cuaj.5787

Published online December 21, 2018

\section{$* * *$}

\section{Introduction}

In recent decades, there have been significant advances in the systemic treatment options for patients with metastatic renal cell carcinoma (mRCC) with the introduction of targeted therapies and, more recently, immune checkpoint inhibition. Prior to the introduction of these contemporary therapies for mRCC, two randomized controlled trials identified a survival advantage to performing cytoreductive nephrectomy (CN) followed by interferon alpha-2b versus interferon alpha-2b alone [1, 2]. However, whether CN, defined as nephrectomy in the setting of metastatic disease, provides a similar survival advantage for patients receiving modern systemic therapy has remained controversial with two recent randomized trials calling into question the value of $\mathrm{CN}[3,4]$. In addition, 


\section{KCRNC consensus: Cytoreductive nephrectomy for mRCC}

several important questions remain surrounding the appropriate application of $\mathrm{CN}$, particularly with regards to optimal patient selection and the timing of surgery.

Herein, the Kidney Cancer Research Network of Canada (KCRNC) provides consensus recommendations on the role of $\mathrm{CN}$ in patients with mRCC in order to guide clinicians who manage patients with advanced RCC.

\section{Methods}

\section{Evidence acquisition}

A comprehensive search was conducted to identify studies relevant to the development of this consensus statement. Databases searched included MEDLINE, EMBASE, Cochrane Central Register of Controlled Trials, Cochrane Database of Systematic Reviews, and SCOPUS. The search strategy was designed and conducted by an experienced librarian with input from the consensus statement authors. The full search strategy can be found in the appendix.

\section{Consensus statement development}

This consensus document was developed to address six questions related to $\mathrm{CN}$ that were judged to be the most relevant to patient care:

1) Should patients with mRCC be offered CN and what is the optimal patient selection and timing?

2) Is there a role for $\mathrm{CN}$ in patients with non-clear cell mRCC?

3) Is there a role for biopsy prior to CN?

4) Is there a role for concomitant regional lymph node dissection during CN?

5) Is there a preferred surgical approach for CN?

The statements contained herein were developed by consensus of the authors of this document, which include stakeholders across multiple specialties. 


\section{Should patients with metastatic renal cell carcinoma be offered cytoreductive nephrectomy and what is the optimal patient selection and timing?}

1. Recognizing the complex nature of advanced kidney cancer management, decisions regarding $\mathrm{CN}$ should ideally be made in a multidisciplinary setting.

2. Patients with a good performance status (ECOG $\leq 1$ or KPS $\geq 80 \%$ ), minimal symptoms related to metastases, a resectable primary tumor, and a limited burden of metastatic disease should be offered upfront $\mathrm{CN}$ followed by metastases directed therapy, a period of surveillance or systemic therapy.

3. Patients with significant systemic symptoms from metastatic disease, active central nervous system metastases, a limited burden of disease within the kidney relative to the cumulative extra -renal volume of metastases, rapidly progressing disease, a poor performance status (ECOG $>1$ or KPS $<80 \%$ ), and/or limited life expectancy should not undergo $\mathrm{CN}$.

4. Patients with mRCC but without characteristics of (2) or (3) should be offered initial treatment with systemic therapy with consideration of $\mathrm{CN}$ given to those with a significant clinical response.

Beyond the clinical trials performed prior to the modern era, several recent studies have investigated the role of $\mathrm{CN}$ in patients receiving targeted therapy. The Clinical Trial to Assess the Importance of Nephrectomy (CARMENA) randomized patients with mRCC to CN followed by sunitinib therapy or sunitinib without CN[3]. Contrary to the clinical trials performed in the pre-targeted therapy era, CARMENA did not identify a survival advantage to undergoing CN prior to systemic therapy. Including 452 patients with a median follow-up 50.2 months, sunitinib alone was found to be non-inferior to CN followed by sunitinib with regards to overall survival (HR 0.89; 95\% CI $0.71-1.10$ ). Furthermore, no significant difference was identified in progression-free survival or response to treatment. There are noteworthy limitations to this trial. Most importantly, $44 \%$ of patients included in CARMENA had poor-risk disease as classified by the Memorial Sloan Kettering Cancer Center (MSKCC) Prognostic Model and the remaining patients had intermediate risk disease. This trial was not designed to test whether CN provides a survival advantage among mRCC patients with favorable risk characteristics. CARMENA accrued 21\% less patients than initially planned over a long time period (8 years) casting some statistical doubt on the results. Furthermore, systemic therapy in CARMENA consisted of sunitinib whereas the first line systemic treatment for mRCC continues to evolve with the use of different targeted therapies and combinations of checkpoint inhibitors proven more active than sunitinib for intermediate and poor risk patients [5]. These limitations notwithstanding, CARMENA is the best available data on 
$\mathrm{CN}$ in patients with mRCC, and the findings suggest that $\mathrm{CN}$ does not provide a survival advantage in a significant proportion of patients with mRCC.

In addition to this randomized trial, several retrospective observational studies have investigated whether $\mathrm{CN}$ provides a survival advantage in patients receiving targeted therapy [6-18]. These observational studies are limited to a varying degree by heterogeneous patient populations, selection bias, confounding and as a result, the strength of their evidence and related conclusions regarding the benefits of $\mathrm{CN}$ are limited. Despite these limitations, nearly all available observational studies have identified a significant survival advantage in favor of $\mathrm{CN}$ for patients treated with targeted therapies [6-18]. For example, in a well performed analysis from the International Metastatic Renal Cell Carcinoma Database Consortium (IMDC) (one of only two studies including Canadian patients), a 40\% reduction in all-cause mortality was noted among patients receiving $\mathrm{CN}$ after controlling for known biases and adjustment for confounders [13]. Similar findings have been noted across many other multi-institutional and population-based studies [6, 7, 9-12, 14-16, 18].

Overall, although CARMENA did not identify an overall survival advantage to CN, the available evidence suggests that $\mathrm{CN}$ may provide a survival advantage in select patients but not in all comers. Risk stratification and patient selection for $\mathrm{CN}$ remains difficult. Multiple studies have investigated factors associated with both survival after CN and response to $\mathrm{CN}[7,8,11-13,17-32]$, and a nomogram has been developed and externally validated to aid in the prediction of 6-month and 1-year survival after CN using preoperative clinical variables[19, 33]. However, no validated models exist to predict response to $\mathrm{CN}$. Although the MSKCC[34] and the IMDC[35] prognostic models are widely used to risk stratify patients with mRCC, and have been incorporated into other professional society recommendations on $\mathrm{CN}$ [36], these models have also not been validated to predict response to $\mathrm{CN}$.

In patients with mRCC who are being considered for $\mathrm{CN}$, the optimal timing relative to the initiation of systemic therapy also remains controversial. Initiating systemic therapy prior to CN may provide symptomatic control and disease stabilization or regression for patients with a large tumor burden. In addition, treating patients with initial systemic therapy may allow the identification of patients not likely to benefit from CN; specifically, patients who progress rapidly on systemic therapy have a poor prognosis and are unlikely to derive a survival advantage by undergoing CN. Approximately $30 \%$ of patients who undergo initial targeted therapy prior to planned CN have been found ultimately to not receive $\mathrm{CN}$, with the most common reason being disease progression, suggesting that a trial of initial targeted therapy may help select patients for CN[37-39]. The rationale for upfront $\mathrm{CN}$ is that it has the potential advantages of palliating symptoms related to the primary tumor, elimination of a source of secondary metastases, and improvement in host immune dysfunction. Although systemic therapy decreases the size 
of the primary tumor in a proportion of patients [37, 40-43], the median decrease in size is estimated to be between 7-32\% and the clinical impact of this is questionable [37, 4043]. Furthermore, if the primary tumor increases in size or complexity during systemic therapy, the feasibility of resection may be decreased.

To investigate the optimal timing of CN relative to initiation of systemic therapy, the Immediate Surgery or Surgery After sunitinib Malate in Treating Patients With Metastatic Kidney Cancer (SURTIME) trial, which was presented at the 2017 European Society of Medical Oncology annual meeting, compared upfront CN versus sunitinib followed by $\mathrm{CN}$ among patients with mRCC with a primary endpoint of disease progression at 28 weeks[4]. Overall, the sequence of upfront CN or sunitinib did not impact disease progression at 28 weeks of follow-up (42.0\% versus $42.9 \%$, respectively, $\mathrm{p}>0.99$ ) [4]. Although an advantage was seen in overall survival in the deferred CN group (median OS 32.4 versus 15 months, $\mathrm{p}=0.034$ ), it is difficult to interpret this result in light of the underpowered analysis and the discordance with the disease progression results. Indeed, SURTIME was complicated by significant difficulties with accrual, with an initial target of 458 patients and a final accrual of 99 patients. Furthermore, the choice of PFS as an endpoint represents an important flaw in the context of mRCC, where documented OS benefits are ideally needed in testing of alternative treatment strategies. As a result of these factors, the clinical impact of this trial is limited.

Several retrospective observational studies have investigated whether the timing of CN versus systemic therapy impacts patient outcomes [9, 44, 45]. Two of these studies found no difference in survival with initial CN versus initial targeted therapy[44, 45]. However, these sample sizes were relatively small ( $n=35$ and $n=102)$, limiting their statistical power. A third more recent population-based study from the SEER database, found an increased overall survival among patients receiving initial targeted therapy followed by CN compared with the opposite. Finally, the most recent population based analysis based on a very large patient sample from the United States National Cancer Database found an overall survival benefit among patients with mRCC treated with CN as the initial treatment modality [46].

Considering the available evidence, the results from CARMENA and SURTIME show that systemic therapy should be the priority in patients with mRCC, with CN reserved for very select patients. Recognizing the limitations of the existing data on CN in patients with mRCC, we provide the following recommendations, based on expert consensus.

As advanced kidney cancer management is complex and rapidly evolving, decisions regarding the optimal timing of $\mathrm{CN}$ should ideally be made after appropriate multidisciplinary discussions and should be followed by a detailed and thorough informed consent process. 
In patients with a good performance status (ECOG $>1$ or KPS $<80$ ), no systemic symptoms, a primary tumor that is deemed resectable, and a limited burden of metastatic disease, we recommend offering upfront $\mathrm{CN}$. Following $\mathrm{CN}$, a period of surveillance or metastases directed therapy may be considered in patients with minimal residual disease[47]. In patients with multiple metastatic deposits remaining, systemic therapy should be initiated after $\mathrm{CN}$.

Conversely, in patients with significant systemic symptoms from metastatic disease, active central nervous system metastases, a limited burden of disease within the kidney relative to the volume of metastases, rapidly progressing disease, a poor performance status (ECOG $>1$ or KPS $<80 \%$ ), and/or a limited life expectancy, we recommend against performing CN. If a patient's clinical condition improves, the role of CN can be revisited.

For patients with mRCC who do not fall into one of these two groups, we recommend initial treatment with systemic therapy before consideration of $\mathrm{CN}$. For these patients the duration of therapy before proceeding to $\mathrm{CN}$ remains uncertain but $\mathrm{CN}$ should ideally be considered in the setting of a complete response or meaningful partial response.

In addition to these recommendations, we suggest clinicians take into account a patient's age, general health status, and competing health risks when making decisions regarding the role of $\mathrm{CN}$, as these are surrogate markers of overall survival. Finally, although formal recommendations cannot be made based on the available evidence, the complexity of surgery and the potential for increased morbidity due to anatomic factors (e.g. venous thrombectomy, resection of surrounding organs) should also be considered.

The Consensus Panel also recognized that nephrectomy may provide a purely palliative benefit in select patients with severe symptoms from their primary tumor (e.g. intractable hematuria, paraneoplastic syndromes with majority of tumor burden within the kidney). Decisions regarding surgery in these patients should be individualized, and general recommendations regarding such scenarios cannot be made.

\section{Special considerations}

Is there a role for cytoreductive nephrectomy in patients with non-clear cell metastatic renal cell carcinoma?

1. Patients with non-clear cell mRCC should be offered $C N$ with similar considerations to those with clear cell mRCC.

The majority of available data on CN pertain to patients with clear cell histology, and thus whether CN provides a survival advantage for appropriately selected patients with non-clear cell mRCC remains uncertain. Of note, the two aforementioned trials of 
cytoreductive nephrectomy performed in the interferon era did not include information on histologic subtypes [1, 2], and all three of the modern TKI era phase 3 trials investigating $\mathrm{CN}$ in mRCC have excluded patients with non-clear cell mRCC[4, 48, 49]. Despite this, limited observational data do suggest that $\mathrm{CN}$ may provide a survival advantage in patients with non-clear mRCC[7, 13, 50-53]. In a recent population based study from the SEER database including 575 patients with non-clear cell mRCC who underwent CN and 276 who did not, cancer-specific mortality was significantly lower in patients receiving CN after controlling for available confounders (multivariable HR 0.38; 95\% CI 0.30 0.47)[50]. Furthermore, a subgroup analysis demonstrated that $\mathrm{CN}$ was associated with an improvement in survival among all investigated non-clear cell histological subtypes (chromophobe, papillary, and collecting duct mRCC)[50]. In addition, a recent retrospective study from the IMDC including 353 patients with papillary mRCC noted that patients who underwent $\mathrm{CN}$ had an improved OS compared to those who did not undergo CN (HR 0.62; 95\% CI 0.45-0.85)[54]. Three additional observational studies have reported similar findings $[7,13,52]$. Thus, recognizing very limited data, we suggest that patients with non-clear cell mRCC may be offered CN with similar indications and contraindications to those with clear cell mRCC.

\section{Is there a role for biopsy prior to cytoreductive nephrectomy?}

1. In patients receiving initial systemic therapy, biopsy of the primary lesion or a metastatic deposit should be performed prior to the initiation of therapy.

2. For patients receiving upfront $\mathrm{CN}$, pre-operative biopsy of the kidney tumour or metastatic deposit may be performed if the results of the biopsy will influence management.

In patients proceeding to initial systemic therapy, histologic diagnosis is required in order to guide appropriate systemic treatment. Nonetheless, in a patient with clear evidence of mRCC who is proceeding to upfront $\mathrm{CN}$, biopsy is not absolutely indicated. As noted above, $\mathrm{CN}$ appears to play a role in treating non-clear cell mRCC, and appropriately selected patients can thus proceed directly to $\mathrm{CN}$ without a biopsy. However, if a non-RCC histology is questioned (e.g. radiographic characteristics suggestive of urothelial carcinoma, lymphoma, etc.), a biopsy prior to CN should be performed as the results may significantly alter the patient's subsequent management. 


\section{KCRNC consensus: Cytoreductive nephrectomy for mRCC}

\section{Is there a role for concomitant regional lymph node dissection during cytoreductive nephrectomy?}

1. In patients with mRCC undergoing $\mathrm{CN}$ who do not have clinical evidence of nodal disease, retroperitoneal lymph node dissection is not recommended.

2. Surgical resection of clinically positive lymph nodes may be considered at the time of $\mathrm{CN}$ after weighing the potential for increased surgical morbidity and the uncertain clinical benefit.

The role of regional lymph node dissection (LND) in patients with RCC continues to be debated, including its role in patients undergoing CN. Neither of the trials performed before the introduction of targeted therapy included standardized LND as part of CN[1, 2]. In addition, the modern phase III trials have not mandated LND as a component of $\mathrm{CN}[3,4,48]$. Nonetheless, five retrospective observational studies and one meta-analysis have investigated whether LND during $\mathrm{CN}$ is associated with an improvement in overall survival among patients with mRCC[55-60]. The common finding between these studies is that LND does not appear to impart a survival advantage in mRCC patients. Similar findings have been noted in patients with and without clinically positive lymph nodes[55].

While existing data does not suggest a benefit to LND during CN, several limitations warrant caution before drawing definitive conclusions, most importantly the lack of standardized LND template in all of these studies. Currently, for patients without evidence of clinically positive regional nodes, we do not recommend performing a LND. However, observational studies have identified that the degree of tumor debulking at the time of $\mathrm{CN}$ may be associated with an improvement in survival[22, 61]. The burden of extra-renal metastases should also be taken into account when considering nodal dissection during $\mathrm{CN}$. Thus, recognizing the lack of evidence to guide this decision, we submit that regional LND may be considered at the time of CN for patients with clinically positive nodes, at the discretion of the treating surgeon after considering the potential for increased morbidity associated with LND along with the uncertain clinical benefit.

\section{Is there a preferred surgical approach for cytoreductive nephrectomy?}

1. Cytoreductive nephrectomy can be performed through both minimally invasive and open surgical approaches at the discretion of the treating surgeon.

Several observational studies have shown that minimally invasive CN can be safely performed in select patients with the potential for reduced morbidity, decreased blood 


\section{KCRNC consensus: Cytoreductive nephrectomy for mRCC}

loss, and shorter length of hospital stay[62-67]. Indeed, there is no reason that CN should be approached differently than radical nephrectomy in patients without metastatic disease. Overall, the surgical approach should be decided taking into consideration patient and tumor characteristics, experience of the surgeon, and the potential need for ancillary procedures (e.g. regional lymph node dissection, resection of surrounding organs, and/or venous thrombectomy). Adrenal sparing, when there is no evidence of tumor invasion or metastatic spread and when technically feasible, is appropriate.

\section{Conclusion}

$\mathrm{CN}$ remains an important component in the multimodal treatment of patients with mRCC. The objective of this consensus statement is to aid Canadian clinicians in the appropriate application of $\mathrm{CN}$, based on currently available evidence, in order to improve the care of patients with mRCC. The management of advanced kidney cancer is rapidly evolving, and it will not be feasible to reevaluate the role of CN with the introduction of each new incremental improvement in systemic therapy. We provide these recommendations until new high-quality and relevant evidence becomes available, at which point this consensus statement will be updated. 


\section{References}

1. Mickisch GH, Garin A, van Poppel H, de Prijck L, Sylvester R. Radical nephrectomy plus interferon-alfa-based immunotherapy compared with interferon alfa alone in metastatic renal-cell carcinoma: a randomised trial. Lancet. 2001;358:966-70.

2. Flanigan RC, Salmon SE, Blumenstein BA, Bearman SI, Roy V, McGrath PC, et al. Nephrectomy followed by interferon alfa-2b compared with interferon alfa-2b alone for metastatic renal-cell cancer. The New England journal of medicine. 2001;345:1655-9.

3. Mejean A, Ravaud A, Thezenas S, Colas S, Beauval JB, Bensalah K, et al. Sunitinib Alone or after Nephrectomy in Metastatic Renal-Cell Carcinoma. N Engl J Med. 2018.

4. Bex A, Mulders P, Jewett MA et al. Immediate Surgery or Surgery After Sunitinib Malate in Treating Patients With Metastatic Kidney Cancer. European Society of Medical Oncology annual congress. 2017.

5. Motzer RJ, Tannir NM, McDermott DF, Aren Frontera O, Melichar B, Choueiri TK, et al. Nivolumab plus Ipilimumab versus Sunitinib in Advanced Renal-Cell Carcinoma. N Engl J Med. 2018;378:1277-90.

6. Macleod LC, Odisho AY, Tykodi SS, Holt SK, Harper JD, Gore JL. Comparative Effectiveness of Initial Surgery vs Initial Systemic Therapy for Metastatic Kidney Cancer in the Targeted Therapy Era: Analysis of a Population-based Cohort. Urology. 2017;23:23.

7. Klatte T, Fife K, Welsh SJ, Sachdeva M, Armitage JN, Aho T, et al. Prognostic effect of cytoreductive nephrectomy in synchronous metastatic renal cell carcinoma: a comparative study using inverse probability of treatment weighting. World J Urol. 2017;18:18.

8. Song Y, Du C-X, Zhang W, Sun Y-K, Yang L, Cui C-X, et al. Impact of Cytoreductive Nephrectomy on Survival in Patients with Metastatic Renal Cell Carcinoma Treated by Targeted Therapy. Chin Med J. 2016;129:530-5.

9. Hanna N, Sun M, Meyer CP, Nguyen PL, Pal SK, Chang SL, et al. Survival Analyses of Patients With Metastatic Renal Cancer Treated With Targeted Therapy With or Without Cytoreductive Nephrectomy: A National Cancer Data Base Study. J Clin Oncol. 2016;34:3267-75.

10. de Groot S, Redekop WK, Sleijfer S, Oosterwijk E, Bex A, Kiemeney LALM, et al. Survival in Patients With Primary Metastatic Renal Cell Carcinoma Treated With Sunitinib With or Without Previous Cytoreductive Nephrectomy: Results From a Population-based Registry. Urology. 2016;95:121-7. 
11. Day D, Kanjanapan Y, Kwan E, Yip D, Lawrentschuk N, Davis ID, et al. Benefit from cytoreductive nephrectomy and the prognostic role of neutrophil-tolymphocyte ratio in patients with metastatic renal cell carcinoma. Intern Med J. 2016;46:1291-7.

12. Xiao W-J, Zhu Y, Dai B, Zhang H-L, Ye D-W. Assessment of survival of patients with metastatic clear cell renal cell carcinoma after radical cytoreductive nephrectomy versus no surgery: a seer analysis. Int Braz J Urol. 2015;41:288-95.

13. Heng DYC, Wells JC, Rini BI, Beuselinck B, Lee J-L, Knox JJ, et al. Cytoreductive nephrectomy in patients with synchronous metastases from renal cell carcinoma: results from the International Metastatic Renal Cell Carcinoma Database Consortium. Eur Urol. 2014;66:704-10.

14. Conti SL, Thomas IC, Hagedorn JC, Chung BI, Chertow GM, Wagner TH, et al. Utilization of cytoreductive nephrectomy and patient survival in the targeted therapy era. Int J Cancer. 2014;134:2245-52.

15. Bamias A, Tzannis K, Papatsoris A, Oudard S, Beuselinck B, Escudier B, et al. Prognostic significance of cytoreductive nephrectomy in patients with synchronous metastases from renal cell carcinoma treated with first-line sunitinib: a European multiinstitutional study. Clin Genitourin Cancer. 2014;12:373-83.

16. Abern MR, Scosyrev E, Tsivian M, Messing EM, Polascik TJ, Dudek AZ. Survival of patients undergoing cytoreductive surgery for metastatic renal cell carcinoma in the targeted-therapy era. Anticancer Res. 2014;34:2405-11.

17. You D, Jeong IG, Ahn J-H, Lee DH, Lee J-L, Hong JH, et al. The value of cytoreductive nephrectomy for metastatic renal cell carcinoma in the era of targeted therapy. J Urol. 2011;185:54-9.

18. Choueiri TK, Xie W, Kollmannsberger C, North S, Knox JJ, Lampard JG, et al. The impact of cytoreductive nephrectomy on survival of patients with metastatic renal cell carcinoma receiving vascular endothelial growth factor targeted therapy. J Urol. 2011;185:60-6.

19. Margulis V, Shariat SF, Rapoport Y, Rink M, Sjoberg DD, Tannir NM, et al. Development of accurate models for individualized prediction of survival after cytoreductive nephrectomy for metastatic renal cell carcinoma. Eur Urol. 2013;63:947-52.

20. Abel EJ, Spiess PE, Margulis V, Master VA, Mann M, Zargar-Shoshtari K, et al. Cytoreductive Nephrectomy for Renal Cell Carcinoma with Venous Tumor Thrombus. J Urol. 2017;03:06.

21. Baum YS, Patil D, Huang JH, Spetka S, Torlak M, Nieh PT, et al. Elevated preoperative neutrophil-to-lymphocyte ratio may be associated with decreased overall survival in patients with metastatic clear cell renal cell carcinoma undergoing cytoreductive nephrectomy. Asian J Urol. 2016;3:20-5. 
22. Capitanio U, Abdollah F, Matloob R, Salonia A, Suardi N, Briganti A, et al. Effect of number and location of distant metastases on renal cell carcinoma mortality in candidates for cytoreductive nephrectomy: Implications for multimodal therapy. Int J Urol. 2013;20:572-9.

23. Corcoran AT, Kaffenberger SD, Clark PE, Walton J, Handorf E, Piotrowski Z, et al. Hypoalbuminaemia is associated with mortality in patients undergoing cytoreductive nephrectomy. BJU Int. 2015;116:351-7.

24. Fukushima H, Nakanishi Y, Kataoka M, Tobisu K-I, Koga F. Postoperative Changes in Skeletal Muscle Mass Predict Survival of Patients With Metastatic Renal Cell Carcinoma Undergoing Cytoreductive Nephrectomy. Clin Genitourin Cancer. 2017;15:e229-e38.

25. Gu L, Li H, Wang H, Ma X, Wang L, Chen L, et al. Presence of sarcomatoid differentiation as a prognostic indicator for survival in surgically treated metastatic renal cell carcinoma. J Cancer Res Clin Oncol. 2017;143:499-508.

26. Ishihara H, Kondo T, Yoshida K, Omae K, Takagi T, Iizuka J, et al. Evaluation of Preoperative Aspartate Transaminase/Alanine Transaminase Ratio as an Independent Predictive Biomarker in Patients With Metastatic Renal Cell Carcinoma Undergoing Cytoreductive Nephrectomy: A Propensity Score Matching Study. Clin Genitourin Cancer. 2017;15:598-604.

27. Ito H, Shioi K, Murakami T, Takizawa A, Sano F, Kawahara T, et al. C-reactive protein in patients with advanced metastatic renal cell carcinoma: usefulness in identifying patients most likely to benefit from initial nephrectomy. BMC Cancer. 2012;12:337.

28. Kalogirou C, Mulfinger P, Sokolakis I, Krebs M, Kubler H, Riedmiller H, et al. Preoperative C-Reactive Protein Values as a Potential Component in Outcome Prediction Models of Metastasized Renal Cell Carcinoma Patients Receiving Cytoreductive Nephrectomy. Urol Int. 2017;99:297-307.

29. Ohno Y, Nakashima J, Ohori M, Tanaka A, Hashimoto T, Gondo T, et al. Clinical variables for predicting metastatic renal cell carcinoma patients who might not benefit from cytoreductive nephrectomy: neutrophil-to-lymphocyte ratio and performance status. Int J Clin Oncol. 2014;19:139-45.

30. Pierorazio PM, McKiernan JM, McCann TR, Mohile S, Petrylak D, Benson MC. Outcome after cytoreductive nephrectomy for metastatic renal cell carcinoma is predicted by fractional percentage of tumour volume removed. BJU Int. 2007;100:755-9.

31. Sharma P, Zargar-Shoshtari K, Caracciolo JT, Fishman M, Poch MA, Pow-Sang $\mathrm{J}$, et al. Sarcopenia as a predictor of overall survival after cytoreductive nephrectomy for metastatic renal cell carcinoma. Urol. 2015;33:339.e17-23. 
32. Tatokoro M, Saito K, Iimura Y, Fujii Y, Kawakami S, Kihara K. Prognostic impact of postoperative C-reactive protein level in patients with metastatic renal cell carcinoma undergoing cytoreductive nephrectomy. J Urol. 2008;180:515-9.

33. Marconi L, de Bruijn R, van Werkhoven E, Beisland C, Fife K, Heidenreich A, et al. External validation of a predictive model of survival after cytoreductive nephrectomy for metastatic renal cell carcinoma. World journal of urology. 2018.

34. Motzer RJ, Bacik J, Murphy BA, Russo P, Mazumdar M. Interferon-alfa as a comparative treatment for clinical trials of new therapies against advanced renal cell carcinoma. Journal of clinical oncology : official journal of the American Society of Clinical Oncology. 2002;20:289-96.

35. Heng DY, Xie W, Regan MM, Warren MA, Golshayan AR, Sahi C, et al. Prognostic factors for overall survival in patients with metastatic renal cell carcinoma treated with vascular endothelial growth factor-targeted agents: results from a large, multicenter study. Journal of clinical oncology : official journal of the American Society of Clinical Oncology. 2009;27:5794-9.

36. Bex A, Albiges L, Ljungberg B, Bensalah K, Dabestani S, Giles RH, et al. Updated European Association of Urology Guidelines for Cytoreductive Nephrectomy in Patients with Synchronous Metastatic Clear-cell Renal Cell Carcinoma. European urology. 2018;74:805-9.

37. Powles T, Blank C, Chowdhury S, Horenblas S, Peters J, Shamash J, et al. The outcome of patients treated with sunitinib prior to planned nephrectomy in metastatic clear cell renal cancer. Eur Urol. 2011;60:448-54.

38. Powles T, Sarwar N, Stockdale A, Sarker S-J, Boleti E, Protheroe A, et al. Safety and Efficacy of Pazopanib Therapy Prior to Planned Nephrectomy in Metastatic Clear Cell Renal Cancer. JAMA Oncol. 2016;2:1303-9.

39. Kutikov A, Uzzo RG, Caraway A, Reese CT, Egleston BL, Chen DY, et al. Use of systemic therapy and factors affecting survival for patients undergoing cytoreductive nephrectomy. BJU international. 2010;106:218-23.

40. Abel EJ, Culp SH, Tannir NM, Matin SF, Tamboli P, Jonasch E, et al. Primary tumor response to targeted agents in patients with metastatic renal cell carcinoma. Eur Urol. 2011;59:10-5.

41. Hellenthal NJ, Mansour AM, Hayn MH, Schwaab T. Is there a role for partial nephrectomy in patients with metastatic renal cell carcinoma? Urol. 2013;31:3641.

42. Lane BR, Derweesh IH, Kim HL, O'Malley R, Klink J, Ercole CE, et al. Presurgical sunitinib reduces tumor size and may facilitate partial nephrectomy in patients with renal cell carcinoma. Urologic Oncology: Seminars and Original Investigations. 2015;33:112.e15-.e21. 
43. Rini BI, Garcia J, Elson P, Wood L, Shah S, Stephenson A, et al. The effect of sunitinib on primary renal cell carcinoma and facilitation of subsequent surgery. $\mathrm{J}$ Urol. 2012;187:1548-54.

44. Wood CG, Margulis V. Neoadjuvant (presurgical) therapy for renal cell carcinoma: a new treatment paradigm for locally advanced and metastatic disease. Cancer. 2009;115:2355-60.

45. Stroup SP, Raheem OA, Palazzi KL, Liss MA, Mehrazin R, Kopp RP, et al. Does timing of cytoreductive nephrectomy impact patient survival with metastatic renal cell carcinoma in the tyrosine kinase inhibitor era? A multi-institutional study. Urology. 2013;81:805-11.

46. Bhindi B, Habermann EB, Mason RJ, Costello BA, Pagliaro LC, Thompson RH, et al. Comparative Survival Following Initial Cytoreductive Nephrectomy Versus Initial Targeted Therapy for Metastatic Renal Cell Carcinoma. J Urol. 2018.

47. Rini BI, Dorff TB, Elson P, Rodriguez CS, Shepard D, Wood L, et al. Active surveillance in metastatic renal-cell carcinoma: a prospective, phase 2 trial. Lancet Oncol. 2016;17:1317-24.

48. Verzoni E, Ratta R, Grassi P, Salvioni R, Stagni S, Montone R, et al. TARIBO trial: targeted therapy with or without nephrectomy in metastatic renal cell carcinoma: liquid biopsy for biomarkers discovery. Tumori. 2017:0.

49. Clinical Trial to Assess the Importance of Nephrectomy.

50. Marchioni M, Bandini M, Preisser F, Tian Z, Kapoor A, Cindolo L, et al. Survival after Cytoreductive Nephrectomy in Metastatic Non-clear Cell Renal Cell Carcinoma Patients: A Population-based Study. Eur Urol Focus. 2017;08:08.

51. Carrasco A, Thompson RH, Leibovich BC, Lohse CM, Cheville JC, Boorjian SA. The impact of histology on survival for patients with metastatic renal cell carcinoma undergoing cytoreductive nephrectomy. Indian J. 2014;30:38-42.

52. Aizer AA, Urun Y, McKay RR, Kibel AS, Nguyen PL, Choueiri TK. Cytoreductive nephrectomy in patients with metastatic non-clear-cell renal cell carcinoma (RCC). BJU Int. 2014;113:E67-74.

53. Kassouf W, Sanchez-Ortiz R, Tamboli P, Tannir N, Jonasch E, Merchant MM, et al. Cytoreductive nephrectomy for metastatic renal cell carcinoma with nonclear cell histology. J Urol. 2007;178:1896-900.

54. Jeffrey Graham CW, Frede Donskov, Jae-Lyun Lee, Anna Paola Fraccon, Felice Pasini, Camillo Porta, I. Alex Bowman, Georg A. Bjarnason, D. Scott Ernst, Sun Young Rha, Benoit Beuselinck, Aaron Richard Hansen, Scott A. North, Christian K. Kollmannsberger, Lori Wood, Ulka N. Vaishampayan, Sumanta K. Pal, Toni K. Choueiri, Daniel Yick Chin Heng. Cytoreductive nephrectomy in metastatic papillary renal cell carcinoma: Results from the International Metastatic Renal 
Cell Carcinoma Database Consortium (IMDC). Genitourinary Cancer Symposium 20182018.

55. Gershman B, Thompson RH, Moreira DM, Boorjian SA, Lohse CM, Costello BA, et al. Lymph Node Dissection is Not Associated with Improved Survival among Patients Undergoing Cytoreductive Nephrectomy for Metastatic Renal Cell Carcinoma: A Propensity Score Based Analysis. J Urol. 2017;197:574-9.

56. Faiena I, Salmasi A, Lenis AT, Donin NM, Johnson DC, Bachour K, et al. Overall survival in patients with metastatic renal cell carcinoma and clinical N1 disease undergoing cytoreductive nephrectomy and lymph node dissection. Urol. 2017;02:02.

57. Chipollini J, Abel EJ, Peyton CC, Boulware DC, Karam JA, Margulis V, et al. Pathologic Predictors of Survival During Lymph Node Dissection for Metastatic Renal-Cell Carcinoma: Results From a Multicenter Collaboration. Clin Genitourin Cancer. 2017;17:17.

58. Patel HD, Gorin MA, Gupta N, Kates M, Johnson MH, Pierorazio PM, et al. Mortality trends and the impact of lymphadenectomy on survival for renal cell carcinoma patients with distant metastasis. Can Urol Assoc J. 2016;10:389-95.

59. Feuerstein MA, Kent M, Bernstein M, Russo P. Lymph node dissection during cytoreductive nephrectomy: a retrospective analysis. Int J Urol. 2014;21:874-9.

60. Bhindi B, Wallis CJD, Boorjian SA, Thompson RH, Farrell A, Kim SP, et al. The Role of Lymph Node Dissection in the Management of Renal Cell Carcinoma: A Systematic Review and Meta-Analysis. BJU Int. 2018.

61. Barbastefano J, Garcia JA, Elson P, Wood LS, Lane BR, Dreicer R, et al. Association of percentage of tumour burden removed with debulking nephrectomy and progression-free survival in patients with metastatic renal cell carcinoma treated with vascular endothelial growth factor-targeted therapy. BJU Int. 2010;106:1266-9.

62. Rabets JC, Kaouk J, Fergany A, Finelli A, Gill IS, Novick AC. Laparoscopic versus open cytoreductive nephrectomy for metastatic renal cell carcinoma. Urology. 2004;64:930-4.

63. Nunez Bragayrac L, Hoffmeyer J, Abbotoy D, Attwood K, Kauffman E, Spiess P, et al. Minimally invasive cytoreductive nephrectomy: a multi-institutional experience. World J Urol. 2016;34:1651-6.

64. Matin SF, Madsen LT, Wood CG. Laparoscopic cytoreductive nephrectomy: the M. D. Anderson Cancer Center experience. Urology. 2006;68:528-32.

65. Ganeshappa A, Sundaram C, Lerner MA, Gardner TA. Role of the laparoscopic approach to cytoreductive nephrectomy in metastatic renal-cell carcinoma: does size matter? J Endourol. 2010;24:1289-92. 
66. Eisenberg MS, Meng MV, Master VA, Stoller ML, Rini BI, Carroll PR, et al. Laparoscopic versus open cytoreductive nephrectomy in advanced renal-cell carcinoma. J Endourol. 2006;20:504-8.

67. Blick C, Bott S, Muneer A, Barber NJ, Hindley R, Eden C, et al. Laparoscopic cytoreductive nephrectomy: a three-center retrospective analysis. J Endourol. 2010;24:1451-5.

68. Verzoni E, Ratta R, Grassi P, Salvioni R, Stagni S, Montone R, et al. TARIBO Trial: Targeted Therapy with or without Nephrectomy in Metastatic Renal Cell Carcinoma: Liquid Biopsy for Biomarkers Discovery. Tumori. 2017:tj5000699. 
KCRNC consensus: Cytoreductive nephrectomy for mRCC

\begin{tabular}{|c|c|c|c|c|c|c|c|}
\hline Trial & $\begin{array}{c}\text { Patient } \\
\text { population }\end{array}$ & $\begin{array}{c}\text { Intervention } \\
\text { arm }\end{array}$ & $\begin{array}{c}\text { Control } \\
\text { arm }\end{array}$ & Outcomes & $\begin{array}{l}\text { Sample } \\
\text { size }\end{array}$ & $\begin{array}{r}\text { Median } \\
\text { followup }\end{array}$ & $\begin{array}{c}\text { Results for primary } \\
\text { outcome }\end{array}$ \\
\hline CARMENA[3] & $\begin{array}{l}\text { Clear cell mRCC, } \\
\text { ECOG 0-1, No } \\
\text { prior systemic or } \\
\text { surgical } \\
\text { treatment for } \\
\text { RCC }\end{array}$ & $\begin{array}{l}\text { CN followed by } \\
\text { sunitinib }\end{array}$ & $\begin{array}{l}\text { sunitinib } \\
\text { alone }\end{array}$ & $\begin{array}{c}\text { Primary - OS } \\
\text { Secondary - } \\
\text { Objective } \\
\text { response, PFS, } \\
\text { Treatment } \\
\text { compliance, } \\
\text { Safety and } \\
\text { adverse events }\end{array}$ & $\mathrm{n}=452$ & $\begin{array}{c}50.2 \\
\text { months }\end{array}$ & $\begin{array}{c}\text { HR for OS: } \\
0.89 \text { (95\% CI, } 0.71 \text { to } \\
1.10)\end{array}$ \\
\hline SURTIME [4] & $\begin{array}{l}\text { Clear cell mRCC, } \\
\text { ECOG 0-1, no } \\
\text { prior systemic or } \\
\text { surgical } \\
\text { treatment for } \\
\text { RCC }\end{array}$ & $\begin{array}{l}\text { sunitinib } \\
\text { followed by CN } \\
\text { followed by } \\
\text { sunitinib }\end{array}$ & $\begin{array}{c}\text { CN } \\
\text { followed } \\
\text { by sunitinib }\end{array}$ & $\begin{array}{c}\text { Primary - Disease } \\
\text { progression at } 28 \\
\text { weeks } \\
\text { Secondary - OS, } \\
\text { Objective } \\
\text { response, Safety } \\
\text { and adverse } \\
\text { events }\end{array}$ & $\mathrm{n}=99^{*}$ & $\begin{array}{c}30.9 \\
\text { months }\end{array}$ & $\begin{array}{c}\text { Progression at } 28 \\
\text { weeks }^{* *} \text { : } \\
\text { Upfront CN - } 42.0 \% \\
\text { Upfront sunitinib - } \\
42.9 \% \\
\text { p }>0.99\end{array}$ \\
\hline TARIBO [68] & $\begin{array}{l}\text { Clear cell mRCC, } \\
\text { ECOG 0-1, Good } \\
\text { or intermediate } \\
\text { risk disease, no } \\
\text { prior systemic or } \\
\text { surgical } \\
\text { treatment for } \\
\text { RCC }\end{array}$ & $\begin{array}{c}\text { CN followed by } \\
\text { sunitinib or } \\
\text { Pazopanib }\end{array}$ & $\begin{array}{c}\text { sunitinib or } \\
\text { Pazopanib } \\
\text { alone }\end{array}$ & $\begin{array}{l}\text { Primary - OS } \\
\text { Secondary - } \\
\text { Objective } \\
\text { response, PFS, } \\
\text { Safety and } \\
\text { adverse events, } \\
\text { Biomarker } \\
\text { analysis }\end{array}$ & $\begin{array}{c}\mathrm{n}=270 \\
\text { (estimated) }\end{array}$ & *** & $* * *$ \\
\hline
\end{tabular}

* Initial accrual target was 458 patients. ${ }^{* *}$ Preliminary results presented at the 2017 European Society of Medical Oncology annual meeting. ${ }^{* * *}$ Enrollment ongoing. CI: confidence interval; CN: cytoreductive nephrectomy; HR: hazard ratio; mRCC: metastatic renal cell carcinoma; OS: overall survival; PFS: progression-free survival. 


\section{Appendix}

\section{Search strategy}

Ovid

Database(s): Embase 1988 to 2018 Week 01, EBM Reviews - Cochrane Central Register of Controlled Trials November 2017, EBM Reviews - Cochrane Database of Systematic Reviews 2005 to December 28, 2017, Ovid MEDLINE(R) Epub Ahead of Print, InProcess \& Other Non-Indexed Citations, Ovid MEDLINE(R) Daily and Ovid MEDLINE(R) 1946 to Present

Search Strategy:

\begin{tabular}{|c|c|c|}
\hline $\mid \#$ & Searches & Results \\
\hline 1 & exp Carcinoma, Renal Cell/sc & 5615 \\
\hline 2 & $\begin{array}{l}\text { ((("renal cell" or "collecting duct") adj3 cancer*) or ((renal or kidney or } \\
\text { hypernephroid or "hyper-nephroid" or "Collecting Duct*" or nephroid*) } \\
\text { adj3 (cancer* or neoplasm* or tumor* or tumour* or carcinoma* or } \\
\text { adenocarcinoma* or hypernephroma or "hyper-nephroma*" or } \\
\text { pyelocarcinoma or "pyelo-carcinoma*")) or "grawitz tumor*" or "grawitz } \\
\text { tumour*" or hypernephroma*).ti,ab,hw,kw. }\end{array}$ & 202004 \\
\hline 3 & exp Neoplasm Metastasis/ & 688965 \\
\hline |4 & $\begin{array}{l}\text { ((secondary adj3 (cancer* or neoplasm* or tumor* or tumour* or } \\
\text { carcinoma* or adenocarcinoma* or hypernephroma or "hyper-nephroma*" } \\
\text { or pyelocarcinoma or "pyelo-carcinoma*" or "grawitz tumor*" or "grawitz } \\
\text { tumour*" or hypernephroma*)) or metastas* or metastatic* or } \\
\text { micrometastas* or micrometastatic*).ti,ab,hw,kw. }\end{array}$ & 1243561 \\
\hline 5 & 1 or $(2$ and (3 or 4$))$ & 65767 \\
\hline 6 & Cytoreduction Surgical Procedures/ & 12762 \\
\hline | 7 & $\begin{array}{l}((\text { cytoreduc* or debulk* or radical*) adj3 (nephrectom* or surg* or resect* } \\
\text { or operat*)).ti,ab,hw,kw. }\end{array}$ & 104554 \\
\hline 8 & 6 or 7 & 104554 \\
\hline 9 & 5 and 8 & 7262 \\
\hline 10 & exp survival/ & 911936 \\
\hline 11 & exp death/ & 732815 \\
\hline 12 & exp mortality/ & 1233613 \\
\hline 13 & mortality.fs. & 561511 \\
\hline
\end{tabular}




\begin{tabular}{|c|c|c|}
\hline 14 & exp survival analysis/ & 305801 \\
\hline 15 & (surviv* or death* or mortalit* or fatalit*).mp. & 5568550 \\
\hline 16 & or/10-15 & 5896880 \\
\hline 17 & 9 and 16 & 3998 \\
\hline ||18 & $\begin{array}{l}\text { limit } 17 \text { to english language [Limit not valid in CDSR; records were } \\
\text { retained] }\end{array}$ & 3472 \\
\hline 19 & limit 18 to $y r=" 2004$-Current" & 2852 \\
\hline 20 & $\begin{array}{l}\text { limit } 19 \text { to (letter or conference abstract or editorial or erratum or note or } \\
\text { addresses or autobiography or bibliography or biography or blogs or } \\
\text { comment or dictionary or directory or interactive tutorial or interview or } \\
\text { lectures or legal cases or legislation or news or newspaper article or overall } \\
\text { or patient education handout or periodical index or portraits or published } \\
\text { erratum or video-audio media or webcasts) [Limit not valid in } \\
\text { Embase,CCTR,CDSR,Ovid MEDLINE(R),Ovid MEDLINE(R) Daily } \\
\text { Update,Ovid MEDLINE(R) In-Process,Ovid MEDLINE(R) Publisher; } \\
\text { records were retained] }\end{array}$ & 871 \\
\hline 21 & 19 not 20 & 1981 \\
\hline 22 & (exp animals/ or exp nonhuman/) not exp humans/ & 9466935 \\
\hline 23 & \begin{tabular}{|l} 
((alpaca or alpacas or amphibian or amphibians or animal or animals or \\
antelope or armadillo or armadillos or avian or baboon or baboons or beagle \\
or beagles or bee or bees or bird or birds or bison or bovine or buffalo or \\
buffaloes or buffalos or "c elegans" or "Caenorhabditis elegans" or camel or \\
camels or canine or canines or carp or cats or cattle or chick or chicken or \\
chickens or chicks or chimp or chimpanze or chimpanzees or chimps or cow \\
or cows or "D melanogaster" or "dairy calf" or "dairy calves" or deer or dog \\
or dogs or donkey or donkeys or drosophila or "Drosophila melanogaster" or \\
duck or duckling or ducklings or ducks or equid or equids or equine or \\
equines or feline or felines or ferret or ferrets or finch or finches or fish or \\
flatworm or flatworms or fox or foxes or frog or frogs or "fruit flies" or \\
"fruit fly" or "G mellonella" or "Galleria mellonella" or geese or gerbil or \\
gerbils or goat or goats or goose or gorilla or gorillas or hamster or hamsters \\
or hare or hares or heifer or heifers or horse or horses or insect or insects or \\
jellyfish or kangaroo or kangaroos or kitten or kittens or lagomorph or \\
lagomorphs or lamb or lambs or llama or llamas or macaque or macaques or \\
macaw or macaws or marmoset or marmosets or mice or minipig or \\
minipigs or mink or minks or monkey or monkeys or mouse or mule or
\end{tabular} & 8138953 \\
\hline
\end{tabular}




\section{KCRNC consensus: Cytoreductive nephrectomy for mRCC}

\begin{tabular}{|c|c|c|}
\hline & $\begin{array}{l}\text { mules or nematode or nematodes or octopus or octopuses or orangutan or } \\
\text { "orang-utan" or orangutans or "orang-utans" or oxen or parrot or parrots or } \\
\text { pig or pigeon or pigeons or piglet or piglets or pigs or porcine or primate or } \\
\text { primates or quail or rabbit or rabbits or rat or rats or reptile or reptiles or } \\
\text { rodent or rodents or ruminant or ruminants or salmon or sheep or shrimp or } \\
\text { slug or slugs or swine or tamarin or tamarins or toad or toads or trout or } \\
\text { urchin or urchins or vole or voles or waxworm or waxworms or worm or } \\
\text { worms or xenopus or "zebra fish" or zebrafish) not (human or humans or } \\
\text { patient or patients)).ti,ab,hw,kw. }\end{array}$ & \\
\hline & 21 not (22 or 23$)$ & 1977 \\
\hline 25 & (case adj3 report).mp,pt. & 2281039 \\
\hline 26 & 24 not 25 & 1798 \\
\hline & remove duplicates from 26 & 1051 \\
\hline
\end{tabular}


$\underline{\text { Scopus }}$

1 TITLE-ABS-KEY((("renal cell" or "collecting duct") W/3 cancer*) or ((renal or kidney or hypernephroid or "hyper-nephroid" or "Collecting Duct*" or nephroid*) W/3 (cancer* or neoplasm* or tumor* or tumour* or carcinoma* or adenocarcinoma* or hypernephroma or "hyper-nephroma*" or pyelocarcinoma or "pyelo-carcinoma*")) or "grawitz tumor*" or "grawitz tumour*" or hypernephroma*)

2 TITLE-ABS-KEY((secondary W/3 (cancer* or neoplasm* or tumor* or tumour* or carcinoma* or adenocarcinoma* or hypernephroma or "hyper-nephroma*" or pyelocarcinoma or "pyelo-carcinoma*" or "grawitz tumor*" or "grawitz tumour*" or hypernephroma*)) OR metastas* OR metastatic* OR micrometastas* OR micrometastatic*)

3 TITLE-ABS-KEY(((cytoreduc* or debulk* or radical*) W/3 (nephrectom* or surg* or resect* or operat*)))

4 TITLE-ABS-KEY(surviv* or death* or mortalit* or fatalit*)

5 PUBYEAR AFT 2003 AND LANGUAGE(english)

$6 \quad 1$ and 2 and 3 and 4 and 5

7 TITLE-ABS-KEY((case W/3 report))

$8 \quad 6$ and not 7

9 TITLE-ABS-KEY((alpaca OR alpacas OR amphibian OR amphibians OR animal OR animals OR antelope OR armadillo OR armadillos OR avian OR baboon OR baboons OR beagle OR beagles OR bee OR bees OR bird OR birds OR bison OR bovine OR buffalo OR buffaloes OR buffalos OR "c elegans" OR

"Caenorhabditis elegans" OR camel OR camels OR canine OR canines OR carp OR cats OR cattle OR chick OR chicken OR chickens OR chicks OR chimp OR chimpanze OR chimpanzees OR chimps OR cow OR cows OR "D melanogaster" OR "dairy calf" OR "dairy calves" OR deer OR dog OR dogs OR donkey OR donkeys OR drosophila OR "Drosophila melanogaster" OR duck OR duckling OR ducklings OR ducks OR equid OR equids OR equine OR equines OR feline OR felines OR ferret OR ferrets OR finch OR finches OR fish OR flatworm OR flatworms OR fox OR foxes OR frog OR frogs OR "fruit flies" OR "fruit fly" OR "G mellonella" OR "Galleria mellonella" OR geese OR gerbil OR gerbils OR goat OR goats OR goose OR gorilla OR gorillas OR hamster OR hamsters OR hare OR hares OR heifer OR heifers OR horse OR horses OR insect OR insects OR jellyfish OR kangaroo OR kangaroos OR kitten OR kittens OR lagomorph OR lagomorphs OR lamb OR lambs OR llama OR llamas OR macaque OR macaques OR macaw OR macaws OR marmoset OR marmosets OR mice OR minipig OR minipigs OR mink OR minks OR monkey OR monkeys OR mouse OR mule OR mules OR nematode OR nematodes OR octopus OR octopuses OR orangutan OR 
"orang-utan" OR orangutans OR "orang-utans" OR oxen OR parrot OR parrots OR pig OR pigeon OR pigeons OR piglet OR piglets OR pigs OR porcine OR primate OR primates OR quail OR rabbit OR rabbits OR rat OR rats OR reptile OR reptiles OR rodent OR rodents OR ruminant OR ruminants OR salmon OR sheep OR shrimp OR slug OR slugs OR swine OR tamarin OR tamarins OR toad OR toads OR trout OR urchin OR urchins OR vole OR voles OR waxworm OR waxworms OR worm OR worms OR xenopus OR "zebra fish" OR zebrafish) AND NOT (human OR humans or patient or patients))

$10 \quad 8$ and not 9

11 DOCTYPE(le) OR DOCTYPE(ed) OR DOCTYPE(bk) OR DOCTYPE(er) OR DOCTYPE(no) OR DOCTYPE(sh) OR DOCTYPE(ab)

1210 and not 11

13 PMID( $\left.0^{*}\right)$ OR PMID(1*) OR PMID(2*) OR PMID(3*) OR PMID(4*) OR PMID(5*) OR PMID(6*) OR PMID(7*) OR PMID(8*) OR PMID(9*)

$14 \quad 12$ and not 